\title{
DISTRIBUIÇÃO GRANULOMÉTRICA DOS SOLOS E O DESENVOLVIMENTO DOS ESCORREGAMENTOS RASOS NA SERRA DO MAR (SP)
}

\author{
Rebeca Durço Coelho $^{(a)}$, Bianca Carvalho Vieira ${ }^{(b)}$, Maria Carolina Villaça Gomes ${ }^{(\mathrm{c})}$, Tiago \\ Damas Martins $^{(\mathrm{d})}$
}

\author{
(a) Departamento de Geografia/FFLCH, USP, E-mail: rebeca.durso@gmail.com \\ (b) Departamento de Geografia/FFLCH, USP, E-mail:biancacv@usp.br \\ (c) Departamento de Geociências/ UEPG, E-mail: mcarolvg@ yahoo.com.br \\ (d) Departamento de Ciências Geográficas/ UFPE, E-mail: martins.td@ gmail.com
}

\section{Eixo: GEOGRAFIA FÍSICA E DESASTRES NATURAIS}

\begin{abstract}
Resumo
A deflagração dos escorregamentos rasos está relacionada a diversos fatores geológicos, geomorfológicos e pedológicos, dentre estes as propriedades físico-mecânicas do solo. Na Serra do Mar, grande parte das rupturas ocorreram no contato entre o solo residual/solo saprolítico, no qual se encontram diferenças pedológicas significativas. Deste modo, a presente pesquisa teve como objetivo principal identificar a relação entre a distribuição granulométrica dos solos e a ocorrência dos escorregamentos rasos na bacia do Rio Guaxinduba, em Caraguatatuba (SP), área fortemente atingida por escorregamentos durante as intensas chuvas de março de 1967. Para tal, foram executados: a) Sondagens e coletas de amostras em dois pontos: P1 (estável) e P2 (instável); b) Granulometria e c) Aplicação da Relação Silte/Argila. Os resultados mostraram que o P1, devido aos elevados teores de areia, que aumentam progressivamente com a profundidade, não favorece a ocorrência dos escorregamentos, enquanto o $\mathrm{P} 2$, com descontinuidades mecânicas/hidrológicas, é mais propenso à sua instabilização durante eventos pluviométricos intensos.
\end{abstract}

Palavras chave: Bacia do rio guaxinduba, propriedades físicas dos solos, Caraguatatuba.

\section{Introdução}

Os escorregamentos são processos geomorfológicos frequentes em ambiente montanhoso e/ou escarpado e ocorrem nos mais diversos ambientes e em praticamente todas condições climáticas (FERNANDES e AMARAL, 1996; HIGHLAND e BOBROWSKY, 2008). Tais processos possuem feições alongadas e sua superfície de ruptura acompanha as descontinuidades mecânicas e/ou hidrológicas presentes no interior do solo, ocorrendo geralmente em profundidades que variam entre 0,5m e 5,0m (FERNANDES e AMARAL, 1996). A compreensão de sua dinâmica, sobretudo em relação aos mecanismos de deflagração, é fundamental para a previsão de áreas suscetíveis a tais fenômenos bem como para a prevenção de situações que provoquem perdas econômicas e sociais.

Como exemplo desses casos tem-se a Serra do Mar, que devido suas características naturais (altas declividades, solos pouco a moderadamente desenvolvidos e elevados índices pluviométricos) e de uso e 
XVII Simpósio Brasileiro

de Geografia Física Aplicada

I Congresso Nacional

de Geografia Física
OS DESAFIOS DA GEOGRAFIA FÍSICA NA FRONTEIRA DO CONHECIMENTO

Instituto de Geociências - Unicamp

Campinas - SP

28 de Junho à 02 de Julho de 2017

ocupação (algumas regiões densamente ocupadas), constitui-se em um ambiente de alta suscetibilidade à ocorrência de escorregamentos. No último século, grandes eventos catastróficos ligados a estes processos geomorfológicos aconteceram nas áreas escarpadas da Serra do Mar, com destaque para aqueles ocorridos em 1967 na região de Caraguatatuba - São Paulo (Figura 1a) e na Serra das Araras (Figura 1b) - Rio de Janeiro.
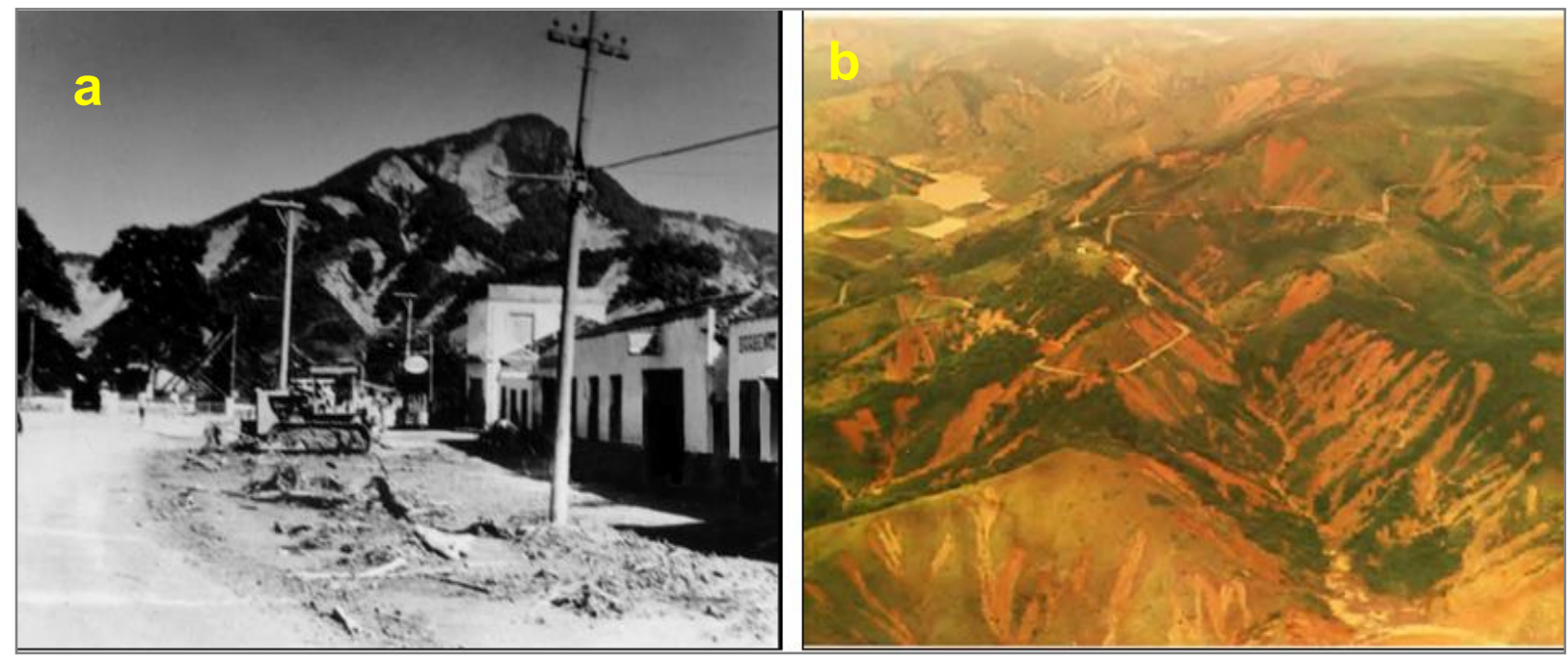

Figura 1: a) Deslizamentos nas vertentes no município de Caraguatatuba em 1967 (Fonte: Prefeitura Municipal de Caraguatatuba); b) Deslizamentos na Serra das Araras em 1967. (Fonte: Jones, 1973)

Mesmo sendo considerada uma área de elevada suscetibilidade natural, a existência de núcleos de ocupação ao longo de toda a sua extensão, sobretudo urbanos, despertou, desde a década de 1960, a necessidade de realização de estudos geológico-geotécnicos (ex. COSTA NUNES, 1969; JONES, 1973; IPT, 1986; VARGAS JR et al, 1986; LACERDA, 1997) e geomorfológicos (ex. MEIS e SILVA 1968; CRUZ, 1974; DE PLOEY e CRUZ, 1979 e etc.), buscando compreender os mecanismos de deflagração dos escorregamentos rasos.

Dentre as diversas metodologias existentes para previsão de áreas suscetíveis aos escorregamentos, como os modelos matemáticos em bases físicas (LOPES, 2006; VIEIRA, 2007; NERY, 2011), bem como para a elaboração de cartas de risco (CERRI, 1993; AUGUSTO FILHO, 1994 entre outros), são diversos os fatores controladores levados em conta, mas nem sempre esses trabalhos contemplam dados físicomecânicos do solo. Considerando que, na Serra do Mar, parte dos escorregamentos rasos se inicia no contato solo residual/solo saprolítico, a compreensão da variação das propriedades do solo, como a granulometria, é de extrema importância para entender parte dos fatores condicionantes dos escorregamentos. 
No ano de 1967, os escorregamentos ocorridos entre os dias 17 e 18 de março de 1967 tiveram sua deflagração, segundo Cruz (1974), no contato entre o solo bem desenvolvido (residual maduro) e o material saprolítico (residual jovem) abaixo. Em outros locais tal ruptura se deu entre este solo bem desenvolvido e um material mais heterogêneo abaixo, mostrando a presença de blocos de diferentes diâmetros envolvidos por uma matriz mais fina (CRUZ, 1974). Assim, esses materiais, que contêm mais areia e menos argila, atingem rapidamente o limite de liquidez, que, por sua vez, estão presos à plasticidade das argilas que dependem das formas e do teor de água (SHOAEI e SIDLE, 2009).

Ainda que haja o conhecimento da importância destas características dos materiais, bem como de sua variação em profundidade, há poucos trabalhos, em âmbito nacional, com levantamentos detalhados de campo sobre estas propriedades dos solos (GUIDICINI e NIEBLE, 1984). Deste modo, o presente trabalho teve como objetivo identificar a relação entre a distribuição granulométrica dos solos e o desenvolvimento de escorregamentos rasos na Serra do Mar paulista.

\section{Metodologia}

Para a realização deste trabalho foi selecionada a bacia do rio Guaxinduba (figura 2), uma vez que existem muitos registros da ocorrência de escorregamentos pretéritos (cicatrizes) e estas possuem acesso. Além disso, nesta bacia são verificadas características representativas da Serra do Mar, tais como: (i) a presença de encostas íngremes (acima de 20); (ii) predomínio de complexos ígneo-metamórficos constituídos de granitoides, gnaisses facoidal, leptito, dentre outros (Almeida, 1964); (iii) notável controle estrutural no relevo e na rede de drenagem (Cruz, 1974); (iv) elevados índices pluviométricos e; (v) presença da mata atlântica de encosta e de altitude.

A partir do mapa de cicatrizes gerado pelo Grupo de Pesquisas de Processos Morfodinâmicos e Ambientais (GPMorfo), foram selecionados dois pontos: o P1, que se encontra em uma área sem evidências de ocorrência de escorregamentos e o P2, que se localiza próximo ao limite de uma cicatriz, confirmados em campo. Ressalta-se que para a escolha do P2 também foram utilizados os seguintes critérios: (i) área sem intervenção antrópica direta, (ii) limites bem preservados e (iii) facilidade de acesso para estudos de campo. 

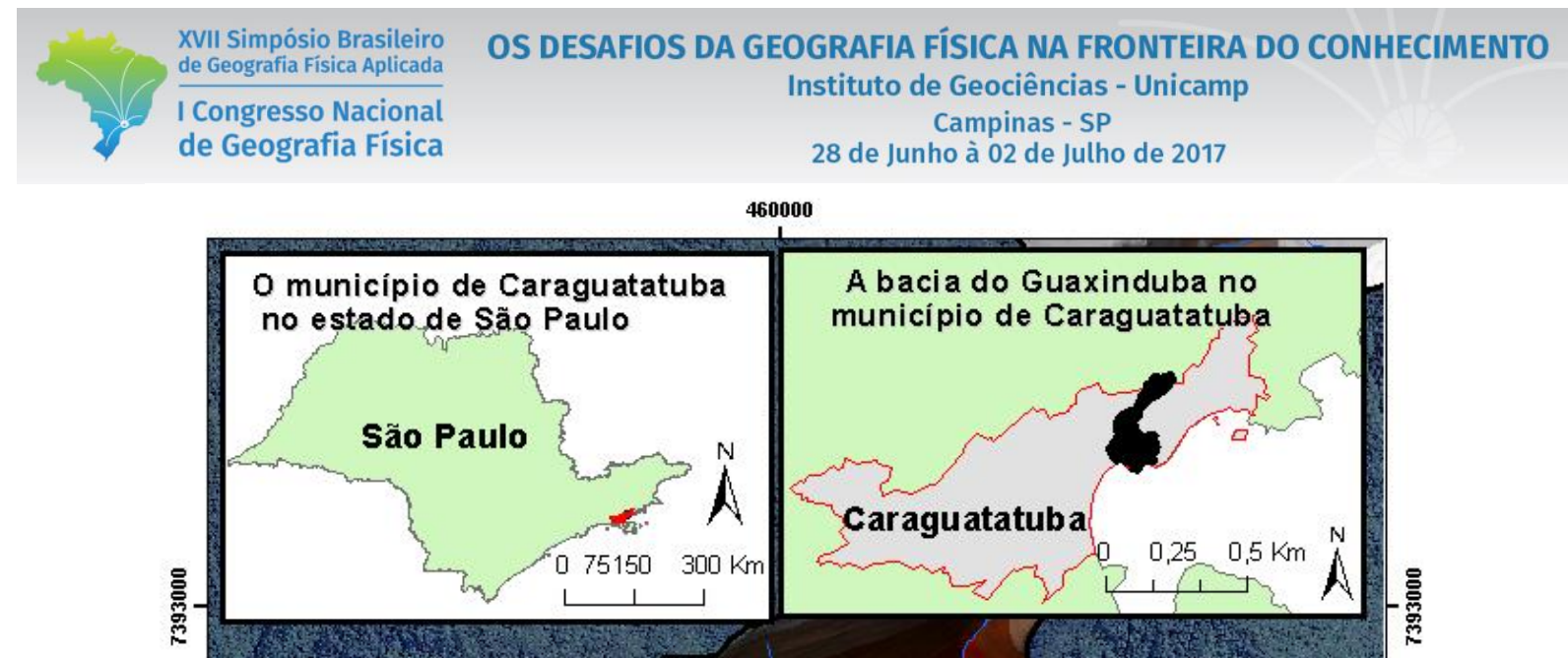

\section{BACIA HIDROGRÁFICA DO RIO GUAXINDUBA}

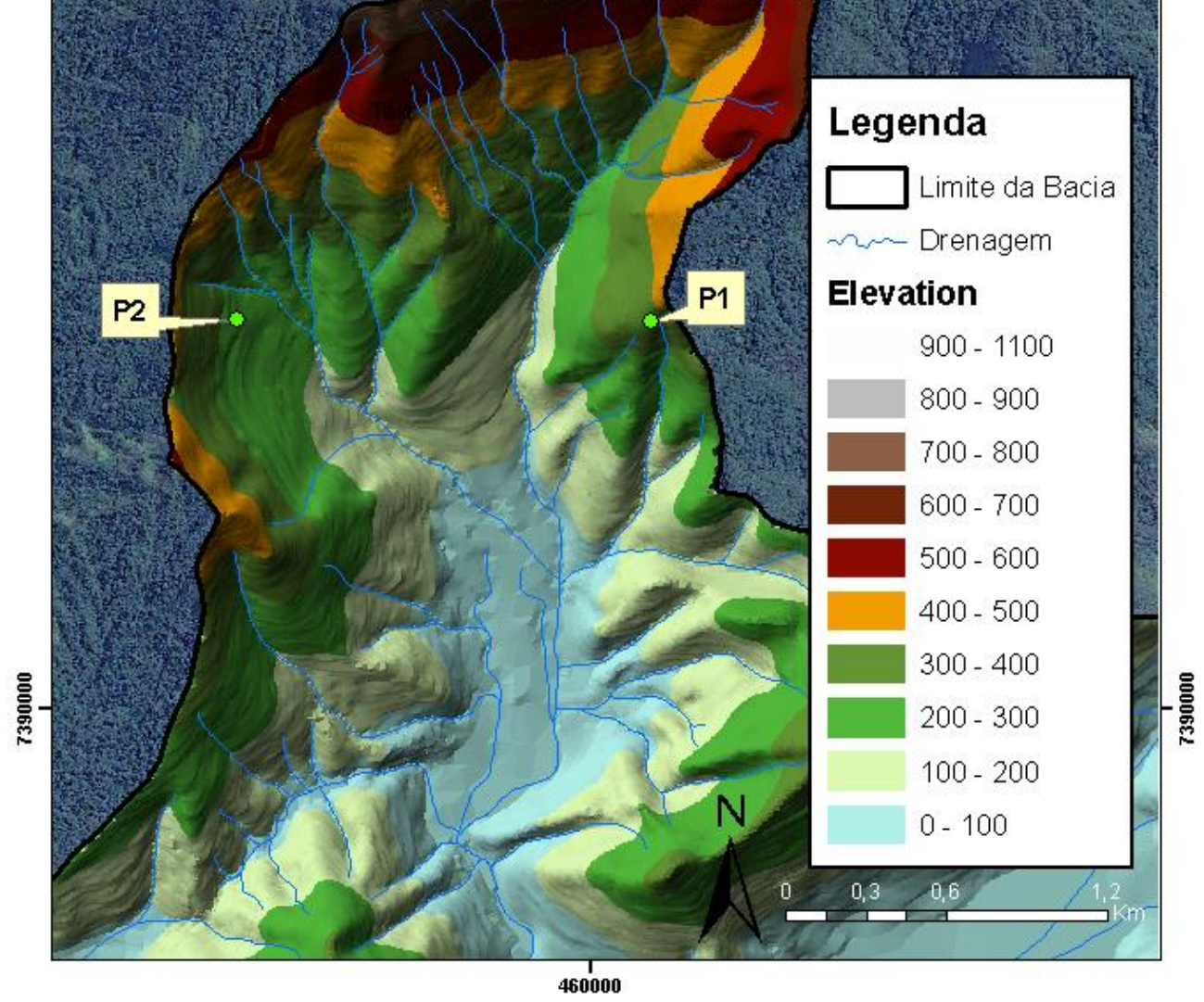

Figura 2: Localização da bacia do rio guaxinduba e dos pontos de coleta

Para os levantamentos de campo, em cada um dos pontos foram realizadas sondagens com um trado holandês ao longo das seguintes profundidades: 0,3m;0,6m;0,9m;1,2m;1,5m;1,8m;2,1m;2,4m;2,7m; e 3m. As coletas foram realizadas à medida que foram observadas alterações de cor e textura do solo, totalizando 20 amostras (Figura 3). Após as coletas, o material foi encaminhado para o Laboratório de Pedologia da Universidade de São Paulo (Laboped), onde foram realizados os procedimentos referentes ao ensaio granulométrico. 


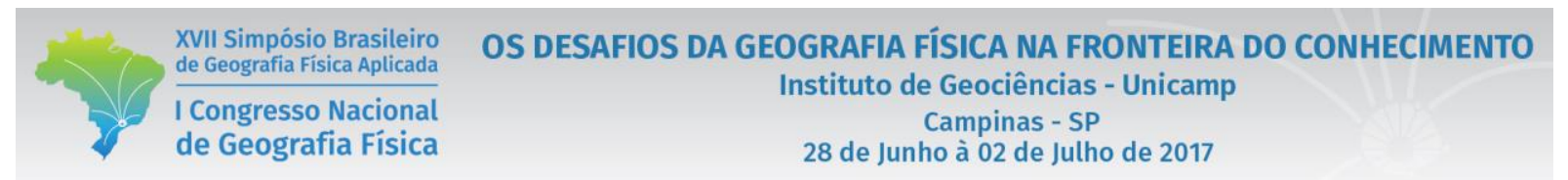

A partir da distribuição granulométrica foi aplicado um índice que representa o grau de intemperismo dos solos - a Relação Silte/Argila - que consiste na razão entre o teor total da fração silte e o teor total da fração argila.
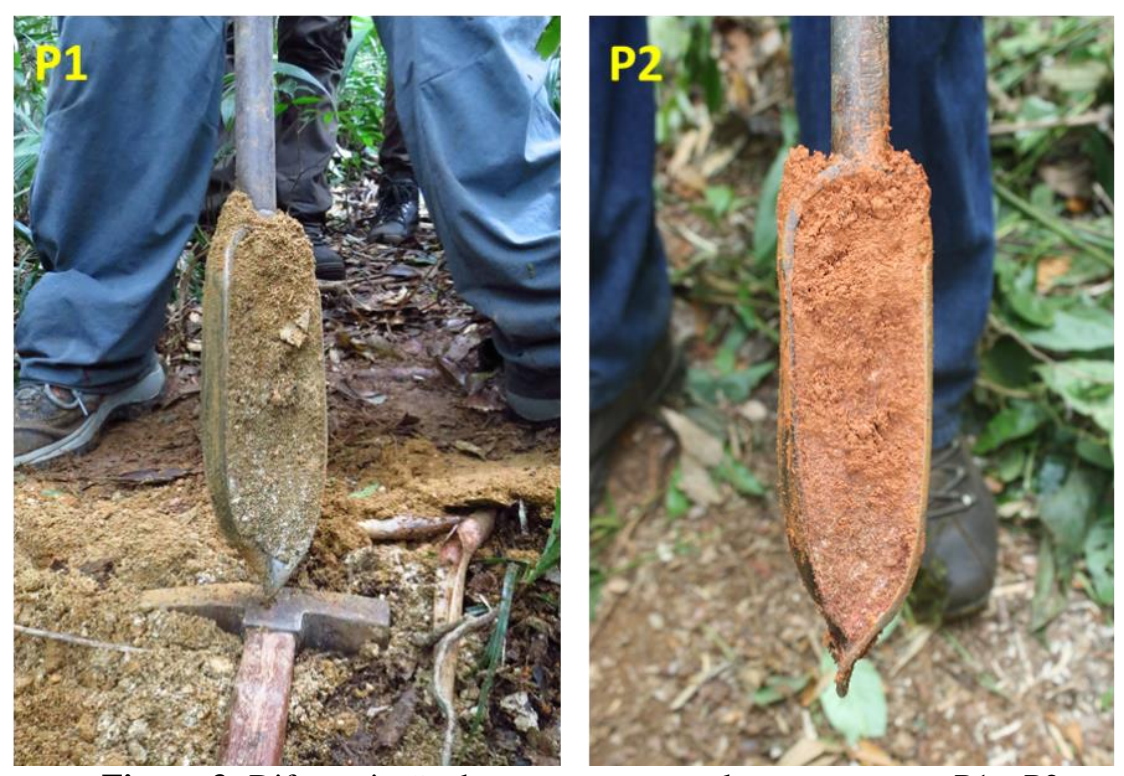

Figura 3: Diferenciação de cores entre as coletas nos pontos P1 e P2. Foto: Rebeca Coelho, 2014 (a) e 2015(b).

\section{Resultados e Discussão}

Os dois pontos apresentaram predominantemente matriz franco-arenosa (Figura 4), ainda que algumas profundidades amostradas sejam constituídas de um teor expressivo de argila, considerando-se as condições topográficas de ambos os pontos. Além dos altos teores de areia, observou-se a tendência de aumento com a profundidade. As frações silte e argila variaram entre $14 \%$ e $64 \%$ e $0 \%$ e $45 \%$, respectivamente. Não se reconhece um padrão de distribuição do silte ao longo dos perfis, mas o teor de argila diminuiu expressivamente.

O ponto $1(\mathrm{P} 1)$, situado em um local sem evidências de ocorrência de escorregamentos, não apresentou variações granulométricas abruptas. Houve uma redução do teor de argila com a profundidade (de $18 \%$ aos $0,3 \mathrm{~m}$ para $3,7 \%$ aos $3 \mathrm{~m}$ ), assim como do silte (de $24 \%$ aos $0,3 \mathrm{~m}$ para $15 \%$ aos $3 \mathrm{~m}$ ). A fração areia, por sua vez, aumentou progressivamente com a profundidade ( $57 \%$ aos $0,3 \mathrm{~m}$ para $80 \%$ aos $3 \mathrm{~m}$ ), sendo que aproximadamente a metade desta fração, ao longo de todo o perfil, era composta por areia média (Figura $5)$. 


\begin{tabular}{|c|c|}
\hline $\begin{array}{l}\text { XVII Simpósio Brasileiro } \\
\text { de Geografia Fisica Aplicada } \\
\end{array}$ & $\begin{array}{l}\text { OS DESAFIOS DA GEOGRAFIA FÍSICA NA FRONTEIRA DO CONHECIMENTO } \\
\text { Instituto de Geociências - Unicamp }\end{array}$ \\
\hline $\begin{array}{l}\text { I Congresso Nacional } \\
\text { de Geografia Física }\end{array}$ & $\begin{array}{l}\text { Campinas - SP } \\
28 \text { de Junho à } 02 \text { de Julho de } 2017\end{array}$ \\
\hline
\end{tabular}

No ponto 2 (P2), localizado próximo a uma cicatriz de escorregamento, houve maior variação da granulometria com a profundidade, possuindo uma maior concentração de argila próximo à superfície
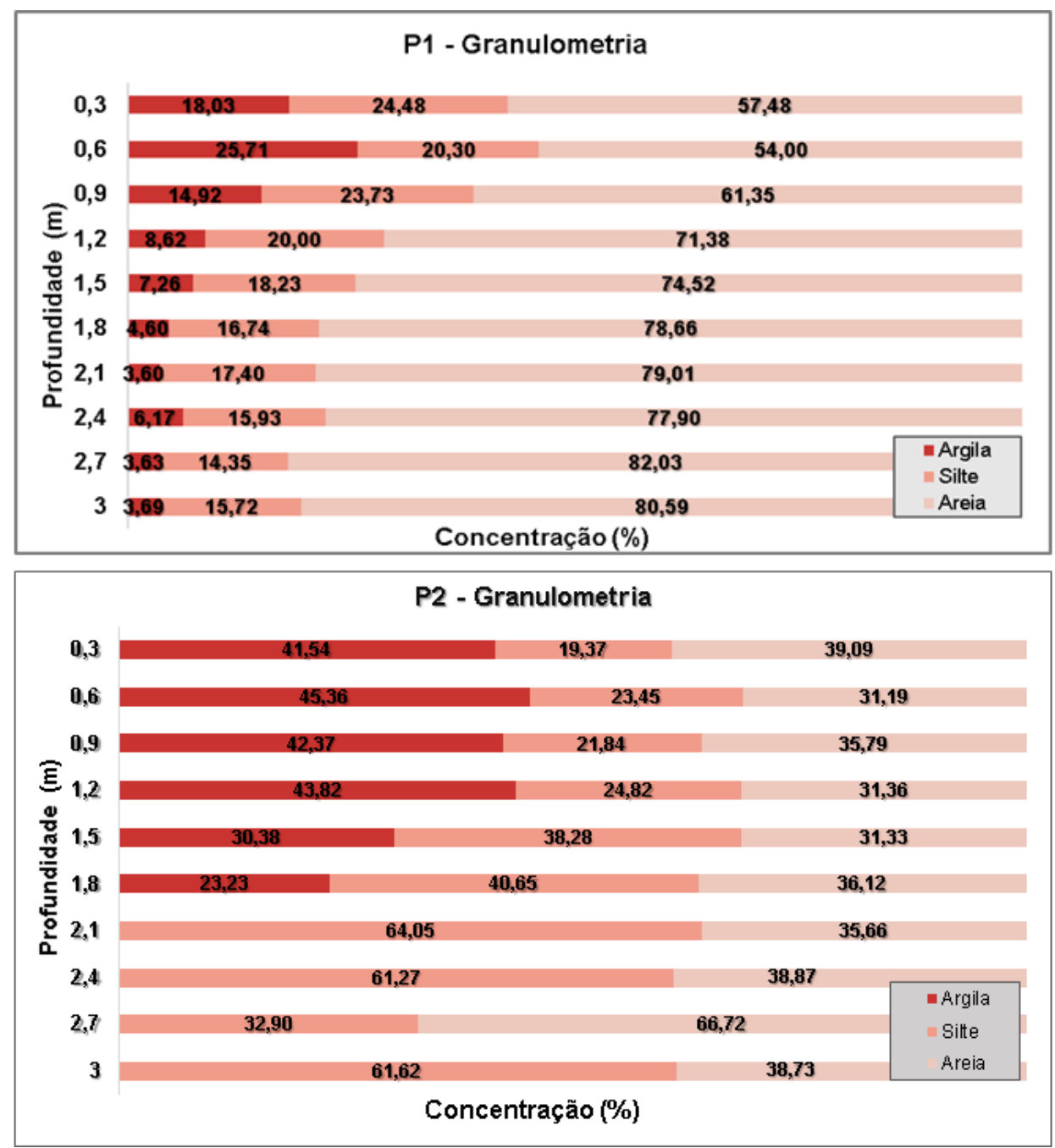

Figura 4: Concentrações de areia, silte e argila no ponto 1 e 2. 

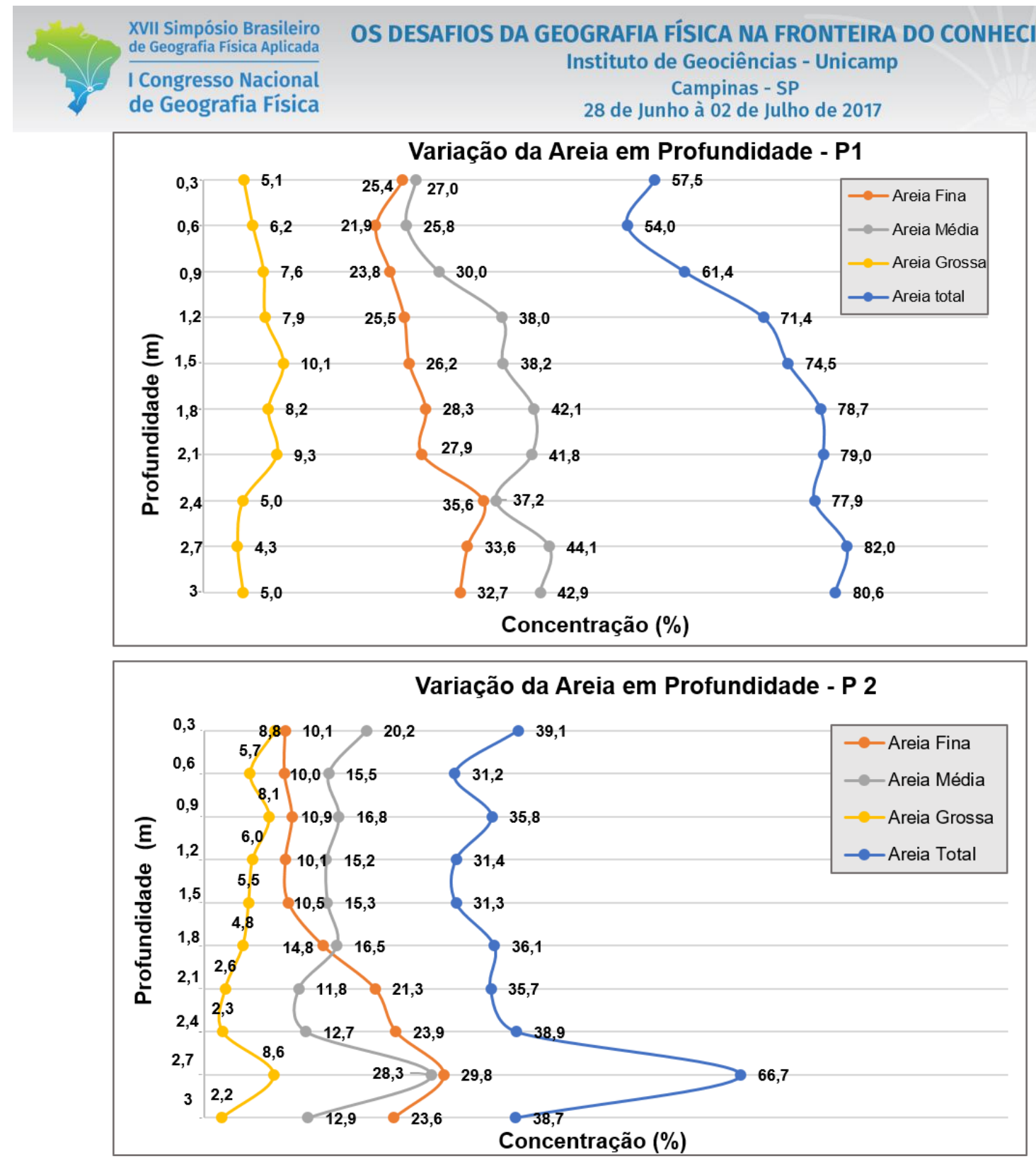

Figura 5: Variação em profundidade dos teores de areia nos pontos 1 e 2 .

(cerca de 40\%). O teor de areia pouco variou em profundidade, (de 31 a $38 \%$ entre 0,6 e 2,4m), tendo havido um aumento abrupto em $2,7 \mathrm{~m}(66,7 \%)$. Já o teor de argila diminuiu progressivamente até os 1,8m, apresentando valores insignificantes a partir desta profundidade, enquanto o silte aumentou progressivamente: $19 \%(0,30 \mathrm{~m}), 38 \%(1,50 \mathrm{~m})$ e $61 \%(3,0 \mathrm{~m})$. Quanto às diferentes frações de areia, a areia média mostrou predominância até 1,8m, variando entre $15,2 \%(1,2 \mathrm{~m})$ e $20,2 \%(0,3 \mathrm{~m})$. A partir desta profundidade, a areia fina apresentou os maiores percentuais $(14,8 \%$ aos $1,8 \mathrm{~m}$ a $29,8 \%$ aos $2,7 \mathrm{~m})$. 


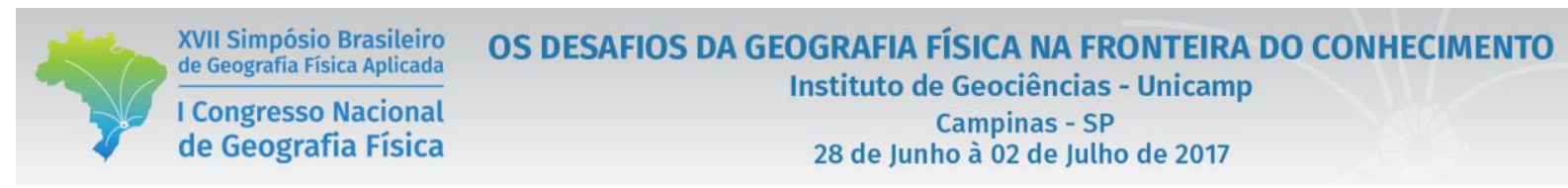

Quanto à relação silte/argila (Figura 6), no P1 houve uma variação de 0,78 a 4,83, predominando valores elevados e uma tendência ao aumento com a profundidade, ou seja, um menor grau de intemperismo do material. No P2, observou-se uma tendência de aumento até 1,8m, no entanto, a amplitude dos valores foi menor $(0,46$ aos $0,3 \mathrm{~m}$ a 1,74 aos $1,8 \mathrm{~m})$. A partir desta profundidade, houve uma redução abrupta dos teores de argila (para aproximadamente $0 \%$ ), e, considerando os teores elevados de silte, resultou em uma relação silte/argila muito alta - entre 32 e 64.

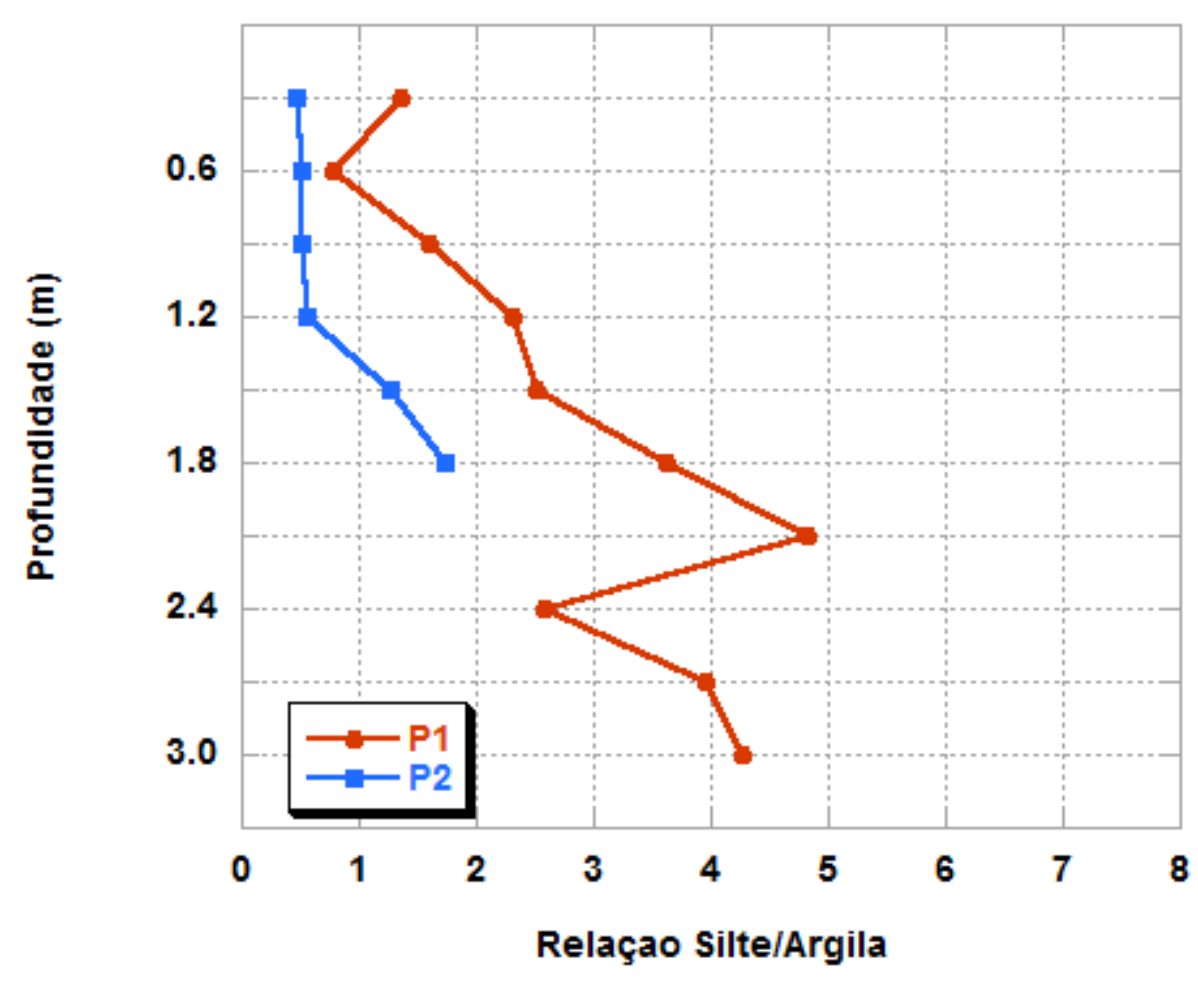

Figura 6: Variação em profundidade da Relação Silte/Argila nos pontos 1 e 2.

O predomínio da fração areia ao longo de todo o perfil P1 bem como o seu aumento com a profundidade favorecem a drenagem vertical da água, que percolaria sem impedimentos até alcançar o saprolito e rocha parcialmente alterada, que se caracterizam por serem muito fraturados na Serra do Mar. Desta forma, a frente de infiltração, mesmo durante eventos pluviométricos intensos e prolongados, não promoveria o desenvolvimento de poro-pressões positivas, uma vez que não há condições favoráveis para a formação de um nível freático suspenso, por exemplo.

No P2, a existência de elevados teores de argila mais próximos à superfície poderia indicar que a drenagem vertical da água não é tão eficiente como no P1. No entanto, essa argila pode contribuir para 
uma melhor agregação do solo, favorecendo a drenagem até a profundidade em que estas ocorrem em totais elevados $(1,2 \mathrm{~m})$. A maiores profundidades há uma quantidade muito expressiva de silte (entre $60 \mathrm{e}$ 65\%), que não contribui tão efetivamente para a estruturação do solo e, portanto, não lhe confere uma boa drenagem. Assim, este perfil estaria sujeito ao aumento do grau de saturação quando do avanço da frente de percolação a maiores profundidades, podendo levar à instabilização da encosta.

\section{Considerações finais}

Considerando que ambos os pontos (P1 e P2) se localizam, de acordo com os dados geológicos, sobre o mesmo litotipo, constatou-se diferenças quanto ao grau de intemperismo, o que certamente influencia a dinâmica da água no manto de alteração. A comparação entre os dois perfis permite concluir que o P2, em área próxima a uma cicatriz, se mostrou mais propenso à instabilidade.

Espera-se que este trabalho possa auxiliar no entendimento das propriedades físicas do solo que possam influenciar no desenvolvimento dos escorregamentos rasos em uma paisagem geomorfológica como a Serra do Mar. Nesse sentido, os dados também colaboraram para indicar a necessidade de maior disponibilidade de dados pedológicos coletados in situ, visando incrementar a base de dados locais para utilização em modelos de previsão de áreas suscetíveis a escorregamentos rasos.

Estudos futuros em diferentes áreas, com novas coletas de solos e avaliações de outras propriedades mecânicas, se fazem necessários para uma maior acurácia e interpretação dos resultados. Espera-se, assim, contribuir também para a definição de áreas para monitoramento hidrológico em tempo real de áreas de elevada instabilidade na Serra do Mar.

\section{Bibliografia}

ALMEIDA, F.F.M. (1964) Fundamentos geológicos do relevo paulista. In: Geologia do Estado de São Paulo, São Paulo - IG/USP: 56-62.

AUGUSTO FILHO, O. (1994) Cartas de risco de escorregamentos: uma proposta metodológica e sua aplicação no município de Ilhabela (SP). São Paulo. Universidade de São Paulo. Dissertação de Mestrado em Engenharia Civil.

CERRI, L.E.S. (1993) Riscos geológicos associados a escorregamentos: uma proposta para a prevenção de acidentes. São Paulo. Universidade Estadual Paulista Júlio de Mesquita Filho. Tese de Doutorado em Geociências e Meio Ambiente.

COSTA NUNES, A.J. (1969). Landslides in soils of decomposed rock due to intense rainstorms. 7th Int. Confer. On Soil Mech. and Found. Eng. ISSMFE, London, pp. 547-554.

CRUZ, O. (1974) A Serra do Mar e o Litoral na Área de Caraguatatuba - SP. Contribuição à Geomorfologia Litorânea Tropical. Tese de Doutorado. IG - Série Teses e Monografias nº 11. .181pp.

DE PLOEY, J; CRUZ, O. (1979) Landslides in the Serra do Mar, Brazil. Catena, 6:111-122. Doi: 10.1016/03418162(79)90001-8. 
FERNANDES, N.F; AMARAL, C. P. (1996) Movimentos de Massa: Uma abordagem GeológicaGeomorfológica in: Geomorfologia e Meio ambiente. Rio de Janeiro: 10ª ed. Bertrand do Brasil, 394 pp.

FERREIRA, F. S. (2013). Análise da influência das propriedades físicas do solo na deflagração dos escorregamentos translacionais rasos na Serra do Mar (SP) [online]. São Paulo: Faculdade de Filosofia, Letras e Ciências Humanas, Universidade de São Paulo, 2013a. Dissertação de Mestrado em Geografia Física. [acesso junho de 2014]. Disponível em: <http://www.teses.usp.br/teses/disponiveis/8/8135/tde-27032013-092838/>.

GUIDICINI, G.; NIEBLE, C.M. (1984). Estabilidade de Taludes Naturais e de Escavação. São Paulo: $2^{\text {a }}$ ed. Edgar Blücher, .194p.

HIGHLAND, L.M.; BOBROWSKY, P, (2008). O manual de deslizamento - Um Guia para a compreensão de deslizamentos. Reston, Virginia, U.S. Geological Survey Circular 1325, 129p. [acesso abril de 2014]. Versão em português disponível em: < https://www.gfdrr.org/sites/gfdrr.org/files/publication/Deslizamentos_M5DS.pdf>.

IPT (Instituto de Pesquisas Tecnológicas do Estado de São Paulo): Indicação preliminar de áreas prioritárias para recomposição da cobertura vegetal na serra do mar na área de Cubatão, Relatório, São Paulo, 1986.

JONES, F.O. (1973) Landslides of Rio de Janeiro and the Serra das Araras Escarpment, Brazil. ,US Geological Survey. Prof. Paper 697. 42 pp.

LACERDA, W.A.(1997) Stability of Natural Slopes Along the Tropical Coast of Brazil In: Proceeding of the International Symposium on Recent Developments in Soil and Pavement Mechanics, M. Almeida, Brookfield, p.1739.

LOPES, E. S. S. (2006). Modelagem espacial dinâmica aplicada ao estudo de movimentos de massa em uma região da serra do mar paulista, na escala de 1:10.000.. xx, $276 \mathrm{f}$. Tese (doutorado) - Universidade Estadual Paulista, Instituto de Geociências e Ciências Exatas, 2006. [Acesso novembro de 2014]. Disponível em: <http://hdl.handle.net/11449/102962>.

MEIS, M.R.M; Meis MRM, Silva JX. (1968). Considerações geomorfológicas a propósito dos movimentos de massa ocorridos no Rio de Janeiro. Revista Brasileira de Geografia, 30, 1: p.55-72.

NERY, T. D. (2011). Avaliação da Suscetibilidade a Escorregamentos Translacionais Rasos na Bacia da Ultrafértil, Serra do Mar (SP). [Online]. São Paulo: Faculdade de Filosofia, Letras e Ciências Humanas, Universidade de São Paulo. Dissertação de Mestrado em Geografia Física. [Acesso outubro de 2014]. Disponível

VARGAS JR, E; OLIVEIRA, A.R.B; COSTA FILHO, L.M; CAMPOS, T.P.(1986) A study of the relationship between the stability of slopes in residual soils and rain intensity, International Symposium on Environmental Geotechnology, Envo Publishing, Leigh, USA, 491-500.

VIEIRA, B.C. Previsão de Escorregamentos Translacionais Rasos na Serra do Mar (SP) a partir de Modelos Matemáticos em Bases Físicas. [Online]. Rio de Janeiro. Universidade Federal do Rio de Janeiro, 2007. Tese de Doutorado em Geografia Física [acesso em outubro de 2014]. Disponível em:http://www.ppgg.igeo.ufrj.br/index.php?option=com_content\&task=view\&id=431\&Itemid=49

VIEIRA, B.C.; FERREIRA, F.S.; GOMES, M.C.V. (2015) Propriedades físicas e hidrológicas dos solos e os escorregamentos rasos na Serra do Mar paulista. Ra' e Ga 34, 269-287.Doi: http://dx.doi.org/10.5380/raega.v34i0.40739.

WOLLE, C.M; HACHICH, W. (1989). Rain-induced landslides in southeastern Brasil. Proceedings 12 ${ }^{\text {th }}$ International Conference Soil Mechanics and Foundation Engineering. Rio de Janeiro, Vol. 2: p.989-994. 